\title{
Determination of Self-Efficacy, Body Image and Sexual Adjustment of Women with Breast Cancer
}

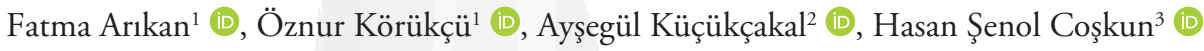 \\ ${ }^{1}$ Akdeniz University Faculty of Nursing, Antalya, Turkey \\ ${ }^{2}$ Department of Medical Oncology, Akdeniz University Hospital, Antalya, Turkey \\ ${ }^{3}$ Department of Medical Oncology, Akdeniz University School of Medicine, Antalya, Turkey
}

\begin{abstract}
Objective: The determination of the self-efficacy levels of women with breast cancer, as well as their body image (BI) and sexual adjustment status, is very important for their empowerment. The purpose of this study was to determine the self-efficacy, BI, and sexual adjustment levels of women with breast cancer that received chemotherapy, as well as the factors that influence these characteristics.

Materials and Methods: This descriptive study included women $(\mathrm{n}=117)$ that were diagnosed with breast cancer, had received at least two sessions of chemotherapy. The study data were collected using a sociodemographic form which also included questions about the breast cancer. Also, the Strategies Used by Patients to Promote Health (SUPPH) scale, and the Sexual Adjustment and Body Image Scale (SABIS) were used.

Results: The average age of the women participating in the study was $56.64 \pm 8.78$ years. In the study, the women with breast cancer undergone a mastectomy, and those who lacked the support of their spouses, as well as education on sexuality, obtained lower scores on the SUPPH and SABIS. There was a positive correlation between the self-efficacy in self-care and sexual adjustment, sexual functions, and body images.

Conclusion: This study found that the women with breast cancer had low self-efficacy, and that their former sexual adjustment and low body image had a negative effect on their post-diagnosis sexual functions.
\end{abstract}

Keywords: Breast cancer, body image, chemotherapy, self-efficacy, sexual adjustment

Cite this articles as: Arıkan F, Körükçü Ö, Küçükçakal A, Coşkun HŞ. Determination of Self-Efficacy, Body Image and Sexual Adjustment of Women with Breast Cancer. Eur J Breast Health 2020; 16(4): 282-289.

\section{Introduction}

Breast cancer is the most common of all types of cancer worldwide. The estimated number of new female breast cancer cases in the United States is 268.600 in $2019(1,2) 55.914$ new female breast cancer cases reported in West Asia in 2018 (3). Breast cancer is ranked first among female cancers in Europe. It is estimated that it affects more than one in every 10 women (4). Incidence rate and prevalence have increased three times in last decades in Turkey. A total of 16.646 women were diagnosed with breast cancer within one year in Turkey (5). Women are being diagnosed with cancer at a younger age; 33.6\% of women that are diagnosed with breast cancer are 54 or younger (6). A woman who is diagnosed with breast cancer has to cope with the traumatic effect of the cancer diagnosis as well as with a number of side effects caused by the cancer treatment. In particular, women may have to face damage to their body image, self-esteem and sexuality, due to alopecia and the loss of their breasts $(7,8)$. Since the breast is also the symbol of being a woman and a mother, losing breasts to mastectomy may be perceived as a loss of femininity and as being deficient as a mother. A deterioration in body image (BI) may have a negative effect on the sexual lives of women and on their family relationships (9). Previous studies have found that women with a positive BI were better at coping with cancer and that a negative BI had a negative effect on women's physical and psychological well-being, as well as on their relationships with their spouses $(9,10)$. Women need to be empowered, and their self-efficacy in self-care should be improved to enable them to cope with the damage to their BI and sexuality. Self-efficacy is correlated with uncertainty, which means that uncertainty or unfamiliar situations cause individuals to feel that they have less control over their own lives, and so their self-efficacy is reduced $(11,12)$. Self-efficacy increases a woman's ability to adapt to the disease and the treatment. Self-efficacy also empowers individuals in the management of symptoms and in the control of side effects, and increases effective self-care behaviours (12-14). For these reasons, determining self-efficacy levels in women with breast cancer, as well as their BI and sexual adjustment status, is very important in teaching 
them positive health behaviours, improving their self-care behaviours, and helping them adapt to the disease. Examining the relationships of these characteristics with sociodemographic variables and with the disease aspects is important as well. This importance was the starting point of this study. The aims of this study are to determine:

1) The self-efficacy, BI, and sexual adjustment levels of women with breast cancer,

2) The effect of cancer recurrence and type of treatment on the levels of women's self-efficacy, sexual adaptation and BI in women with breast cancer, 3) The effect of partner support and taken an education about sexuality on the self-efficacy, sexual adaptation and BI of women during cancer treatment, and

4) The relationship between the self-care, self-efficacy and sexual adjustment and BI levels of breast cancer patients.

\section{Materials and Methods}

\section{The design and sample of the study}

This descriptive study included women $(n=117)$ that were diagnosed with breast cancer, had received at least two sessions of chemotherapy, obtained a 70 or higher score on the Karnofsky Performance Scale, and were older than 18 years. Patients who received less than 2 cycles of chemotherapy without primary cancer were excluded. The study data were collected between February and September 2016. The sample of this study consisted of 117 women with breast cancer who received chemotherapy and met the inclusion criteria at the time of study. The study data were collected by pencil questionnaire survey and the patients' personal information (time elapsed after diagnosis (months), cancer stage, number of chemotherapy treatment sessions, radiotherapy, surgical treatment, hormonotherapy, and targeted treatment) were obtained from their medical records.

\section{Measures}

The Patient Introduction Form included 18 questions in total; 8 of them were about the age, sex and marital status of the patients, and 10 were about the characteristics of their disease, including their diagnoses, the stage of their disease, the treatment they received, and the number of chemotherapy sessions $(9,15)$.

Strategies Used by Patients to Promote Health (SUPPH) is a 29-item scale that was created by Lev and Owen (15) to evaluate self-efficacy levels in individual self-care behaviors. They reported that the range of alpha values of the sub-scales were $0.82-0.93$ and the test-retest stability coefficient was 0.94 . The scale includes three dimensions: coping with stress, decision-making, and developing positive behaviour. The first ten items form the dimension of coping with stress. Items 11, 12 and 13 form the dimension of decision-making, and items 14 to 29 form the

\section{Key Points}

- A woman who is diagnosed with breast cancer may have to face damage to their body image, self-esteem and sexuality.

- The women with breast cancer had low self-efficacy, and that their former sexual adjustment and breast formation had a negative effect on their post-diagnosis sexual functions.

- Low self-efficacy had a negative effect on their post-diagnosis sexual functions.

- A woman who is diagnosed with breast cancer should support by oncology professions for physical, social and emotional caring needs. dimension of positive behavior. Each item is scored from 1 to 5 (1=very little, $5=$ very much). The evaluation is based on adding up the scores given to each one of the items (minimum=29; maximum=145). Higher scores indicate an increase in the self-efficacy level. The scale is valid and reliable for Turkish society, as reported by Akın et al. They found that the Cronbach alpha value for the total scale as 0.92 . That reported that the scale's item-total correlations varied between 0.49 and 0.79 (13). In this study, the Cronbach's alpha value of the scale was 0.93 .

The Sexual Adjustment and Body Image Scale (SABIS) was developed by Dalton et al. (16), consists of 14 items in two scales that assess sexual adjustment and BI. The sexual adjustment scale includes eight items and three subdimensions which are previous sexual adjustment, effect on sexual functionality, and the importance of breasts in sexuality. In the evaluation of the scale, items 1, 2, 7 and 8 in the subdimensions of previous sexual adjustment and the importance of breasts in sexuality are scored from 1 to 5. Items 3, 4, 5 and 6 in the subdimension of the effect on sexual function is evaluated using a Likert-type scale. The scale is evaluated based on the subdimension mean scores, and there is no total score on the scale, but total scores changes between -2 to +2 in subdimension. Lower mean scores on the subdimensions indicate poor sexual adjustment $(16,17)$. The BI scale consists of six items in two dimensions which are previous $\mathrm{BI}$ and prospective BI. The items in the BI scale are evaluated using a Likert-type scale with scores from 1 to 5. Items 1, 2 and 3 assess the BI before breast cancer diagnosis, and items 4, 5 and 6 assess the BI after breast cancer diagnosis. The scale is evaluated based on the subdimension mean scores, and there is no total score on the scale. Lower mean scores on the subdimensions indicate a poor BI. Dalton et al. (16) found that the Cronbach's alpha coefficient ranged from 0.80 to 0.87 for $\mathrm{BI}$ subscales and from 0.66 to 0.91 for sexual adjustment. The test-retest reliability coefficients ranged from 0.66 to 0.81 for subscales. Erol Ursavaş and Karayurt (17) showed that the scale is a valid and reliable measurement tool for Turkish society, Cronbach's alpha value of the SABIS was over 0.77 . They reported that factor loadings ranged from 0.83 to 0.90 for sexual adjustment scales and ranged from 0.52 to 0.86 for the body image scale. In this study, the Cronbach's alpha values was 0.75 for BI scale and 0.76 for sexual adjustment scale.

\section{Statistical analysis}

The statistical analysis of the data was made using IBM Statistical Package for Social Sciences version 19.0 (IBM SPSS Corp.; Armonk, NY, USA) software. The categorical variables were summarized as frequencies and percentages. The normal distribution of data was tested using the Kolmogorov-Smirnov test. Independent groups $t$ test and one-way ANOVA were used to evaluate the effect of type of surgery, time after diagnosis, number of chemotherapy cures, partner support, taken an education about sexuality, cancer recurrence and treatment on self-efficacy, sexual adaptation and body image of women. Spearman's correlation analysis was used to evaluate relationship between self-care self-efficacy and sexual adjustment and body image.

\section{Ethics}

In order to use the scales; the approval from Akin for SUPPH and Karayur for SABIS was taken by e-mail. Furthermore, research permission has been obtained from the Head of the Medical Oncology Department. The researchers also obtained the approval of the ethics board (approval no:70904504/131) as well as the written and verbal permission of the patients in the study. The research was conducted in accordance with the ethical criteria of the Helsinki Declaration, preserving all women's rights and confidentiality. 


\section{Results}

\section{The sociodemographic and disease characteristics}

In total, 117 women participated in the study, and their average age was 56.6 \pm 8.7 years (min: 27; max: 91 years of age). Most of the participants had stage II breast cancer $(60.7 \%)$. Also, $40.9 \%$ of the women had recurrent cancer. In the study, $54.7 \%$ of the women with breast cancer had been diagnosed for at least 12 months, and $63.2 \%$ of them had received two to six chemotherapy sessions. The proportion of the women that had received radiotherapy was $59.8 \%$, those that had received hormonotherapy were at a rate of $19.7 \%$, and those that had received targeted therapy were at a proportion of $43.6 \%$. Also, $44.4 \%$ of the participants had undergone breast-conserving surgery. According to the statements of the women, $13.7 \%$ had been informed by their physicians about the effects of this disease and treatment on their sexual lives, $63.2 \%$ had received information from their nurses, while $23.1 \%$ had received no information at all. Also, $37.7 \%$ of the women believed that the education about sexuality was not sufficient. In the treatment process, $44.5 \%$ of the women received sufficient support from their spouses (Table 1).

\section{Self-efficacy, body image, and sexual adjustment levels}

The item total score of the SUPPH scale, which was used to evaluate the participants' self-efficacy in their self-care, was $35.5 \pm 6.7$, indicating that the patients' self-efficacy during their treatment was weak. Among the women with breast cancer, scores for previous sexual adjustment $(3.3 \pm 1.0)$ and the importance of breasts in sexuality $(3.3 \pm 1.0)$ were moderate, while the score for the effect of breasts on sexual function was low $(0.8 \pm 1.0)$. In addition, scores for their previous BI perceptions $(3.7 \pm 0.8)$ and prospective $\mathrm{BI}$ perceptions $(3.2 \pm 1.2)$ were at a moderate level, while their BI perception scores became lower after they were diagnosed with cancer (Table 2).

\section{The effect of cancer recurrence and type of treatment on levels of women's self-efficacy, sexual adaptation and body image}

This study has determined the effect of a relapse in breast cancer and the type of treatment (radiotherapy, surgical treatment, hormonotherapy, and targeted therapy) on patients' self-care levels, SABIS. The level of self-efficacy in the self-care of the women that did not receive radiotherapy $(37.2 \pm 6.3)$ was higher than in the women that received radiotherapy $(34.4 \pm 6.8)(\mathrm{p}<0.05)$. The study also found that radiotherapy had a negative effect on the self-efficacy level of self-care among the women with breast cancer $(\mathrm{p}<0.05)$. Radiotherapy affected the post-treatment sexual functions of the women negatively $(\mathrm{p}<0.05)$. The study compared women's body images before and after the radiotherapy, and found that the pre-treatment BI of the radiotherapy group was stronger than the $\mathrm{BI}$ of those that did not receive radiotherapy $(3.8 \pm 0.7,3.6 \pm 0.8$, respectively). The level of self-efficacy in self-care was the same in the women that received targeted treatment and in those that did not receive this treatment. However, the negative effect of treatment on sexual functionality in the women that received targeted treatment $(-1.1 \pm 0.6)$ was higher than in those that did not receive this treatment $(-0.6 \pm 0.7)(\mathrm{p}<0.05)$ (Table 3$)$.

The level of self-efficacy in self-care and the development of positive behaviors were higher in the women that had been diagnosed with breast cancer for less than 12 months, than in those that had been diagnosed for longer than 12 months $(\mathrm{p}<0.05$. There was no difference in the sexual adjustment and BI scores of the patients regarding the period of time that had passed since their diagnoses $(p>0.05)$. There of the women that had undergone mastectomy than in those who had had breast-protective surgery as the surgical treatment of choice. The post-treatment $\mathrm{BI}$ became poorer in the women who had undergone a mastectomy (Table 4).

\section{The effect of partner support and taken an education about sexuality on self-efficacy, sexual adaptation and body image}

The perceived spousal support during the cancer treatment process did not have a significant effect on the level of self-efficacy in self-care. The negative effect of this support on sexual function after the diagnosis was also lower $(-0.7 \pm 0.6)$ (Table 5) $(\mathrm{p}<0.05)$. The patients who believed that they had received sufficient education on the effects of cancer treatment on sexuality had a better BI $(\mathrm{p}=0.01)$. Regarding sexual adjustment, the patients had an insufficient sexual adjustment after the treatment, though the group believing that they had received sufficient education had a slightly better sexual adjustment $(\mathrm{p}=0.01)$. The sexuality education that patients had received had no considerable effect on their self-efficacy levels ( $\mathrm{p}>0.05$ ) (Table 4).

\section{Relationship between self-care self-efficacy and sexual adjustment and body image}

We found that there was a moderate, positive, and statistically significant correlation between self-efficacy and sexual adaptation $(r=0.31$, $\mathrm{p}<0.01)$. The women's self-efficacy levels in self-care had a moderate, positive, and statistically significant effect on their sexual functions $(r=0.34, p<0.01)$. In women with breast cancer, self-efficacy had a moderate, positive, and statistically significant effect on BI $(r=0.34$, $\mathrm{p}<0.01$ ) (Table 5).

\section{Discussion and Conclusion}

This study found that the women with breast cancer had low selfefficacy, and that the levels of their previous sexual adjustment and their perception of the importance of breasts in sexuality were at a moderate level. Furthermore, there was a positive correlation between the self-efficacy in self-care among women diagnosed with breast cancer and their sexual adjustment, sexual functions, and body images. In the women with breast cancer, previous and prospective $\mathrm{BI}$ perceptions were at a moderate level, while their BI perceptions became weaker after they were diagnosed with breast cancer. Breast cancer diagnosis had a negative effect on women's post-diagnosis sexual function, and their perception of the importance of breasts in sexuality, as reported by the women in the studies (17-19). Two relevant studies using the same scales found results similar to this study, and determined that women with breast cancer had moderate BI perceptions before and after their diagnoses, and that there was a reduction in their BI scores after the diagnosis $(17,18)$. The characteristic of the sample in our study was that the patients were in active chemotherapy period. This shows that a long and active treatment process has a negative effect on self-efficacy, BI and sexual adjustment problems. Additionally, the patients that had been diagnosed with breast cancer for less than 12 months obtained higher self-efficacy scores in coping and in developing positive behaviours.

Radiotherapy may cause many skin changes because of radiation resulting in worsening of chest wall cosmesis, leading to further worsening of BI as the patient progresses in radiation treatment. Targeted therapies are combined with chemotherapy. Therefore, these patients experience the side effects of chemotherapy, affecting BI and sexuality $(20,21)$. This study found that the women, who did not receive radiotherapy, had higher self-efficacy and sexual functionality was af- 


\section{Table 1. The sociodemographic and disease characteristics of the women ( $n=117)$}

\section{Demographic characteristics}

Age (Mean \pm SD)

$56.6 \pm 8.7(\min : 27 ; \max : 91)$

Education level

n $\quad \%$

Illiterate

$12 \quad 10.3$

Primary school

$62 \quad 53.0$

High school

23

19.7

Collage

Marriage

Married

Single

106

90.6

Child

Have children

99

Have not children

$17 \quad 14.7$

Working status

Yes

No

$27 \quad 23.1$

90

76.9

Income

Income less than expense

Income equal or more than expense

Time elapsed after diagnosis (months)

12 months and below

Over 12 months

Cancer stage

Stage 1

Stage 2

Stage 3

Stage 4

57

48.3

$60 \quad 51.7$

$64 \quad 57.4$

$53 \quad 45.3$

Recurrence

Yes

No

Chronic disease (except cancer)

Yes

No

80

68.4

Number of chemotherapy treatment session

2-6 cures

$74 \quad 63.2$

7-12 cures

Over 12 cures

22

18.8

21

17.9

Radiotherapy

Yes

70

59.8

No
Surgical treatment

Breast conserving surgery

44.4

Mastectomy

49.6

No surgery

6.0

Hormonotherapy

Yes

$23 \quad 19.7$

No

$94 \quad 80.3$

Targeted treatment

$\begin{array}{lll}\text { Yes } & 51 & 43.6 \\ \text { No } & 66 & 56.4\end{array}$

Getting information about the effects of treatment on sexual life

The doctor informed

$16 \quad 13.7$

The nurse informed

$\begin{array}{ll}74 & 63.2\end{array}$

I did not get any information

$27 \quad 23.1$

Level of education on sexuality

Sufficient

$19 \quad 21.2$

Middle

$37 \quad 41.1$

Insufficient

$34 \quad 37.7$

Spouse support

$\begin{array}{lll}\text { Sufficient } & 52 & 44.5\end{array}$

Middle

$34 \quad 29.1$

Insufficient

$30 \quad 25.6$

Single

$1 \quad 0.8$

SD: standard deviation

Table 2. Total item scores of Strategies Used by Patients to Promote Health and The Sexual Adjustment and Body Image Scale $(n=117)$

$\begin{array}{lcc}\text { Scales } & \text { Mean } & \text { SD } \\ \text { SUPPH } & 35.5 & 6.7 \\ \text { Coping with stress } & 34.7 & 8.17 \\ \text { Decision-making } & 9.3 & 3.6 \\ \text { Developing positive behavior } & 62.5 & 11.9 \\ \text { SAS } & 1.20 .5 & \\ \text { Previous sexual adjustment } & 3.3 & 1.0 \\ \text { Effect on sexual functionality } & 0.8 & 0.7 \\ \text { The importance of breasts in sexuality } & 3.3 & 1.0 \\ \text { BIS } & 3.4 & 0.7 \\ \text { Previous body image } & 3.7 & 0.8 \\ \text { Prospective body image } & 3.2 & 1.2\end{array}$

SD: standard deviation; SUPPH: Strategies Used by Patients to Promote Health; SAS: Sexual Adjustment Scale; BIS: Body Images Scale 


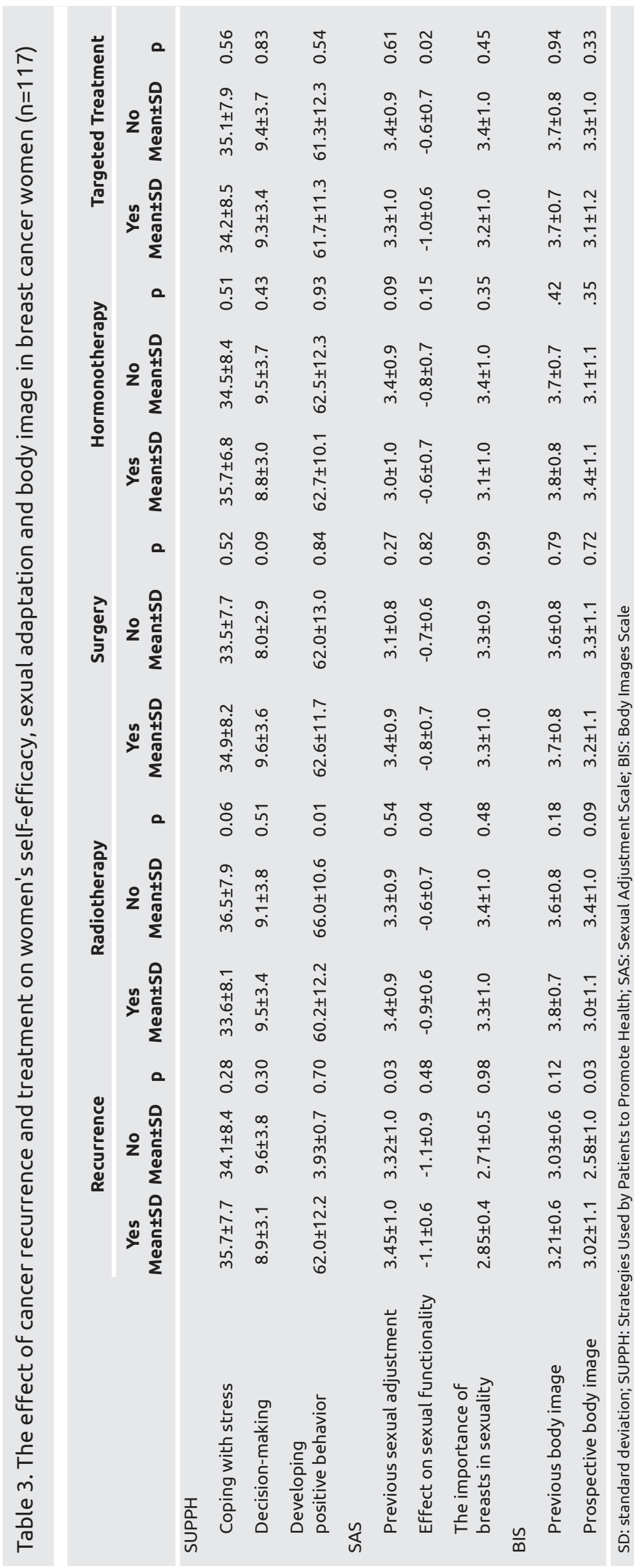

fected negatively in patients who had targeted treatments. It was seen that differences in cancer treatment effects on self-efficacy, BI and sexual adjustment problems and this should be considered in patient counselling. Also, the radiotherapy and targeted treatments had a larger negative influence on the post-diagnosis sexual function (22).

In this study, perceived spousal support during cancer treatment had positive effect on women's self-efficacy in self-care, body image and sexual adjustment $(\mathrm{p}<0.05)$. Researchers have stressed that support from their spouses is important in improved resistance in women with breast cancer, and helped them better cope with the disease (23, 24). If the spouse accepts the change in his wife's body after the diagnosis of breast cancer, and provides support about this issue, it can positively affect post-diagnosis coping (25) and sexual adjustment (26). However, it was also reported that almost half of breast cancer-diagnosed women had negative partner relationships $(27,28)$. This result of the present study is consistent with the relevant literature. Like most patriarchal societies, women's family responsibilities in Turkish society are quite high. Diagnosis of breast cancer carries a woman from the caregiver role to the caregiver role. This situation negatively affects the family and spouse relations of the woman. In our study, it was determined that the majority of women with breast cancer had inadequate spousal support and their relationship with their spouses was negatively affected.

Cancer and cancer treatment have a destructive effect on BI. In the cancer treatment process, women with breast cancer go through changes in their body integrity and appearance (28). Archangelo et al. (29) reported that patients who underwent breast reconstruction after mastectomy had better sexual function and body image and less depressive symptoms than those who had only undergone mastectomy. In this study, the post-treatment BI became poorer in the women who had undergone a mastectomy. Breast is an important element of being feminine in Turkish culture as it is in all cultures. Loss of breast may be seen as a loss of identity or a lack of identity in women and effects women's body image negatively (30). The women who lose their breasts women that have negative thoughts about their physical appearance, have difficulty continuing their normal daily life routines in their domestic and professional lives, with a probable neglect of their sexual lives, which means that they do not have a sexual life $(31,32)$. Women in our study also perceived breast loss as loss of femininity and their sexuality and body image may be negatively affected. In oncology, the changes in BI should be evaluated, considering the length of time that passes after diagnosis, the change in body appearance, and the permanency of the changes in BI $(28,29)$.

Women with breast cancer commonly experience difficulties and education, counselling, and supportive interventions help patients have a better BI and make a better sexual adjustment (33-35). It is recommended that intimacy and sexuality be reintroduced into consultations at every stage of the disease, especially shortly after treatment begins. Moreover, it is emphasized that women with 


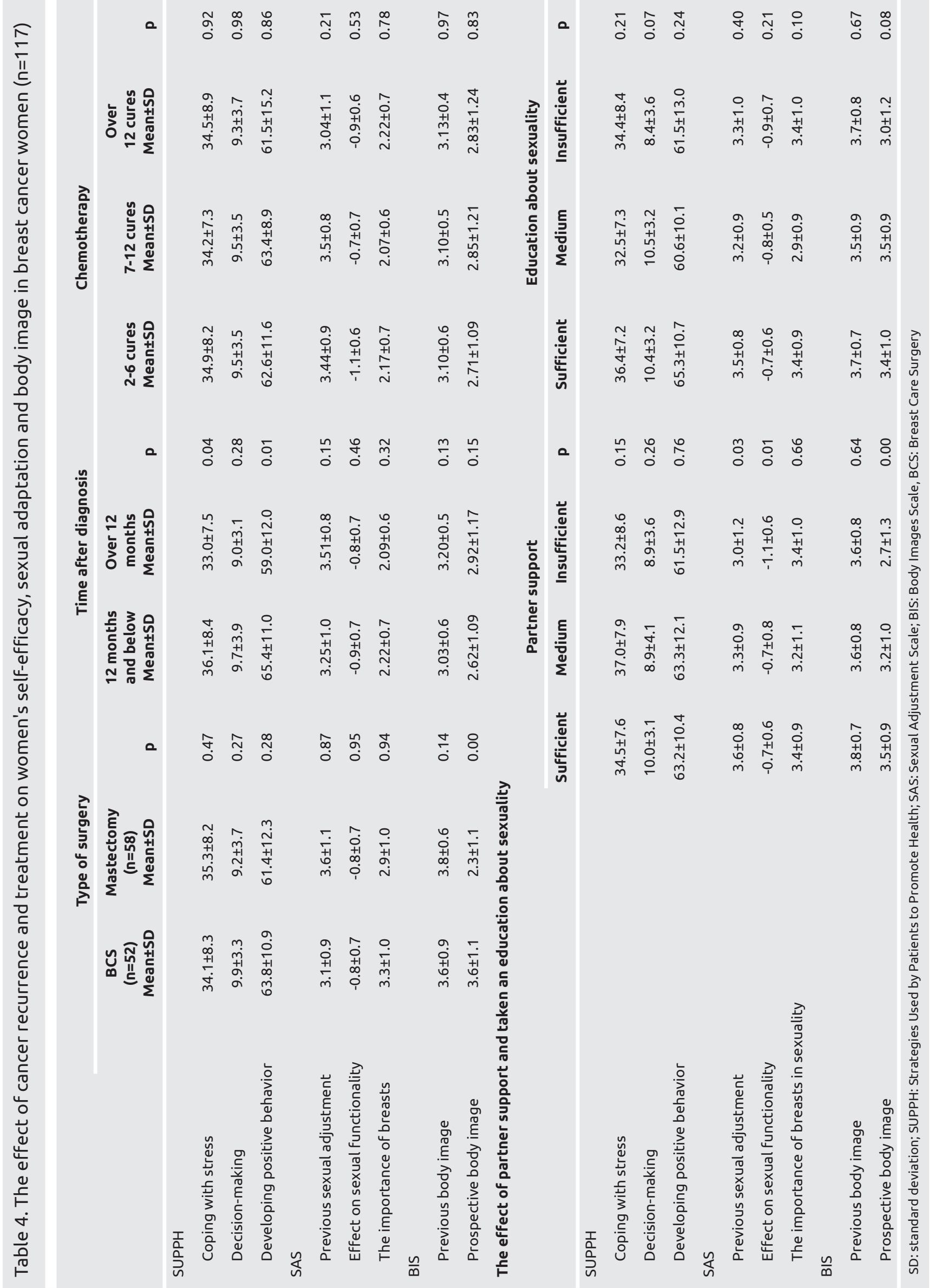




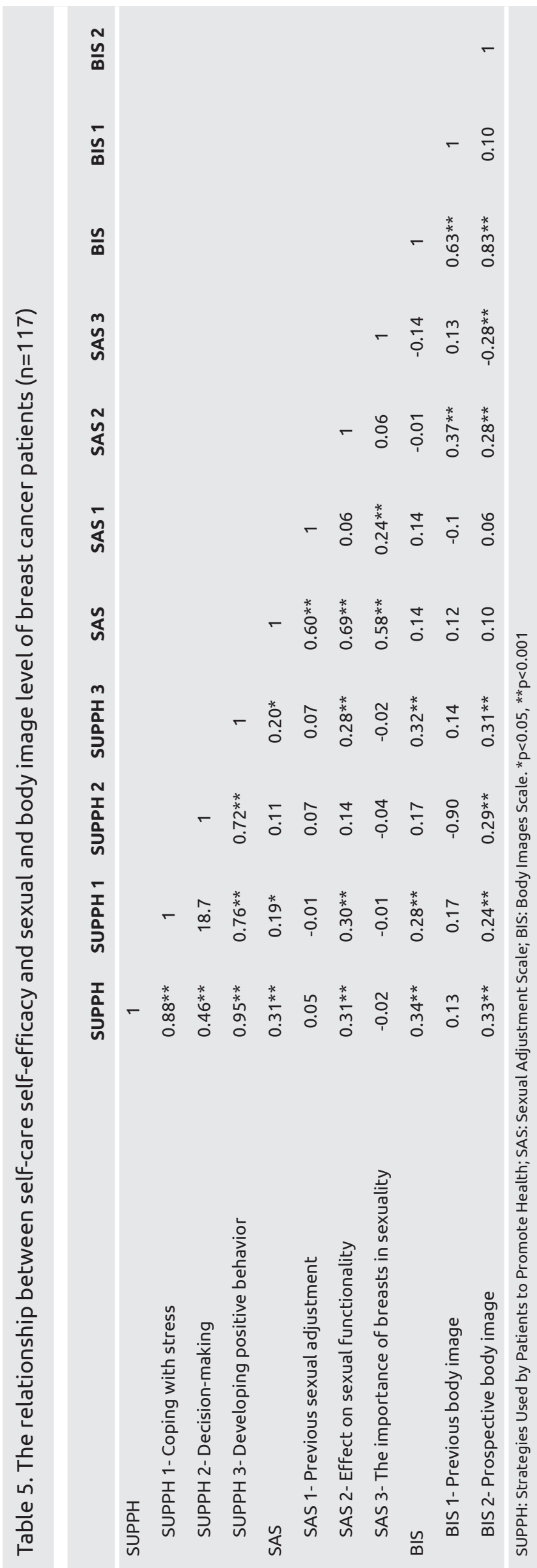

breast cancer expect health professionals to initiate this issue through a personal conversation (35). In this study, the patients who believed that being informed by their physicians and nurses about the effects of cancer and cancer treatment on sexuality was sufficient for them had poorer BI and sexual adjustment. However, they functioned better regarding these aspects than those who were not sufficiently informed, before and after the treatment. The education program provided in the institution where this study was conducted did not include continuous counselling, but rather a preliminary briefing about the side effects of cancer and cancer treatment. Even the provision of this limited information positively affected the post-treatment BI and sexual adjustment of patients. This information is important, since it draws attention to the fact that speaking to patients about these issues is beneficial.

In this study, there was a positive correlation between the self-efficacy in self-care among women diagnosed with breast cancer and their sexual adjustment, sexual functions, and body images. In the women with breast cancer, a reduction in self-efficacy was correlated with increased physical and psychological stress, and with a poorer quality of life (36). Other studies in the relevant literature produced similar results, and found that BI and sexual, adjustment was correlated $(17,37,38)$.

The researcher used only quantitative methods to collect the study data, which is another limitation. The final limitation of the study is that we only evaluated BI and sexual adjustment from a few questions of one tool, which is the most popular, valid and reliable scale in the oncology area.

Oncology nurses play a key role in evaluating problems related to BI and sexual adjustment in breast cancer patients. Nurses also play a role in evaluating problems that can reduce self-efficacy and contribute to a lack of support. For this reason, completing an accurate and thorough description of the influential factors is necessary in learning how to help patients adjust to breast cancer. This study found that women with breast cancer had low self-efficacy, and their previous sexual adjustment and the importance placed on breasts in sexuality were at moderate levels. Also, low self-efficacy had a negative effect on their post-diagnosis sexual functions. Self-efficacy, BI and sexual adjustment were negatively affected when the cancer diagnosis was more than a year old, when radiotherapy and hormone therapy were provided in addition to chemotherapy, when the patient lacked spousal support, and when insufficient information was provided about sexuality. In conclusion, the results of this study might guide nurses, who should be aware that the effects of targeted BC therapy and radiation will have a greater impact on $\mathrm{BI}$, and who can be tuned to the particular needs of this cohort in terms of physical, social and emotional support.

Ethics Committee Approval: Ethical committe approval was obtained from Akdeniz Univeristy Faculty of Medicine Clinical Researches Ethical Commite (Approval no:70904504/131).

Informed Consent: Written informed consent was obtained from patient who participated in this study.

\section{Peer-review: Externally peer-reviewed.}

Author Contributions: Concept - F.A., Ö.K., A.K., H.S.C.; Design - F.A., Ö.K., A.K., H.S.C.; Materials - F.A., A.K.; Analysis and/or Interpretation F.A., Ö.K.; Literature Search - F.A., Ö.K., H.S.C.; Writing Manuscript - F.A., Ö.K.; Critical Review - F.A., H.S.C. 
Financial Disclosure: The authors declared that this study has received no financial support.

\section{References}

1. Siegel RL, Miller KD, Jemal A. Cancer statistics, 2020. CA Cancer J Clin 2020; 70: 7-30. [CrossRef]

2. Siegel RL, Miller KD, Jemal A. Cancer statistics, 2019. CA Cancer J Clin 2019; 69: 7-34. (PMID: 30620402) [CrossRef]

3. Available from: https://hsgm.saglik.gov.tr/depo/birimler/kanser-db/istatis tik/2014RAPOR._uzuuun.pdf Accessed December 3, 2019.

4. Ozmen V. Breast cancer in the world and Turkey. Eur J Breast Health 2008; 4: 6-12.

5. Howlader N, Noone AM, Krapcho M, eds. SEER Cancer Statistics Review, 1975Y2010. Bethesda, MD: National Cancer Institute; 2013. http://seer.cancer.gov/csr/1975_2010/. Accessed March 9, 2019.

6. Annunziata MA, Giovannini L, Muzzatti B. Assessing the body image: relevance, application and instruments for oncological settings. Support Care Cancer 2012; 20: 901-907. (PMID: 22160547) [CrossRef]

7. Deshields TL, Potter P, Olsen S, Liu J. The persistence of symptom burden: symptom experience and quality of life of cancer patients across one year. Support Care Cancer 2014; 22: 1089-1096. (PMID: 24292095) [CrossRef]

8. Manganiello A, Hoga LAK, Reberte LM, Miranda CM, Rocha CAM. Sexuality and quality of life of breast cancer patients post mastectomy. Eur J Oncol Nurs 2011; 15: 167-172. (PMID: 20864400) [CrossRef]

9. Garrusi B, Faezee H. How do Iranian women with breast cancer conceptualize sex and body image? Sex Disabil 2008; 26: 159-165. [CrossRef]

10. Huang $\mathrm{CH}$, Ho MY, Tsai CR. A study of physical activity, uncertainty and health self-efficacy in the patients after percutaneous coronary intervention. Tzu Chi Nurs J 2012; 11: 66-76.

11. Zhang Y, Kwekkeboom K, Petrini M Uncertainty, self-efficacy, and selfcare behavior in patients with breast cancer undergoing chemotherapy in China. Cancer Nurs 2015; 38: 19-26. (PMID: 24945265) [CrossRef]

12. Akin S, Can G, Durna Z, Aydiner A. The quality of life and self-efficacy of Turkish breast cancer patients undergoing chemotherapy. Eur J Oncol Nurs 2008; 12: 449-456. (PMID: 18842460) [CrossRef]

13. Yoo H, Kim CJ, Jang Y, You M. Self-efficacy is associated with selfmanagement behaviours and health status of South Koreans with chronic diseases. Int J Nurs Pract 2011; 17: 599-606. (PMID: 22103826) [CrossRef]

14. Kim SH, Byun Y. Trajectories of symptom clusters, performance status, and quality of life during concurrent chemoradiotherapy in patients with high-grade brain cancers. Cancer Nurs 2018; 41: 38-47. (PMID: 27631114) [CrossRef]

15. Lev EL, Owen SV. A measure of self-care self-efficacy. Res Nurs Health 1996; 19: 421-429. [CrossRef]

16. Dalton EJ, Rasmussen VN, Classen CC, Grumann M, Palesh OG, Zarcone J, Kraemer HC, Kirshner JJ, Colman LK, Morrow GR, Spiegel D. Sexual Adjustment and Body Image Scale (SABIS): a new measure for patients with breast cancer. Breast J 2009; 15: 287-290. (PMID: 19645784) [CrossRef]

17. Erol Ursavaş F, Karayurt Ö. Adaptation of the sexual adjustment and body image scale in Turkish breast cancer women. Int J Nurs Knowl 2015; 27: 162-169. (PMID: 25784437) [CrossRef]

18. Özalp E, Karslıŏlu EH, Aydemir Ö, Soygür H, Erkek BM, Peker SE, Kaymak SU. Validating the sexual adjustment and body image scale (SABIS) with breast Cancer patients. Sex Disabil 2015; 33: 253-267. [CrossRef]

19. Foster C, Breckons M, Cotterell P, Barbosa D, Calman L, Corner J, Fenlon D, Foster R, Grimmett C, Richardson A, Smith PW. Cancer survivors' self-efficacy to self-manage in they ear following primary treatment. J Cancer Surviv 2015; 9: 11-19. (PMID: 25028218) [CrossRef]

20. Sodergren SC, Copson E, White A, Efficace F, Sprangers M, Fitzsimmons D, Bottomley A, Johnson CD. Systematic review of the side effects associated with anti-HER2-targeted therapies used in the treatment of breast cancer, on behalf of the EORTC quality of life group. Target Oncol 2016; 11: 277-292. (PMID: 26677846) [CrossRef]
21. Vomvas D, Iconomou G, Soubasi E, Leotsinidis M, Kalofonos HP, Beratis S, Kardamakis D, Assimakopoulos K. Assessment of sexual function in patients with cancer undergoing radiotherapy-a single centre prospective study. Anticancer Res 2012; 32: 657-664. (PMID: 22287759)

22. Wittenberg L, Yutsis M, Taylor S, Giese-Davis J, Bliss-Isberg C, Star P, Spiegel D. Marital status predicts change in distress and well-being in women newly diagnosed with breast cancer and their peer counselors. Breast J 2010; 16(5): 481-489. (PMID: 20642458) [CrossRef]

23. Dalton WT, Nelson DV, Brobst JB, Lindsay JE, Friedman LC. Psychosocial variables associated with husbands' adjustment three months following wives' diagnosis of breast cancer. J Cancer Educ 2007; 22: 245-249. (PMID: 18067437) [CrossRef]

24. Avci IA, Okanli A, Karabulutlu E, Bilgili N. Women's marital adjustment and hope lessness levels after mastectomy. Eur J Oncol Nurs 2009; 13: 299-303. (PMID: 19520606) [CrossRef]

25. Winch CJ, Sherman KA, Koelmeyer LA, Smith KM, Mackie H, Boyages J. Sexual concerns of women diagnosed with breast cancer-related lymphedema. Support Care Cancer 2015; 23: 3481-3491. (PMID: 25814444) [CrossRef]

26. Tiryaki A, Özçürümez G, Sağlam D, Yavuz M. Responses of spouses of women with breast cancer to the disease. Anatolian Journal of Psychiatr 2010; 11: 95-101.

27. Kraemer LM, Stanton AL, Meyerowitz BE, Rowland JH, Ganz PA. A longitudinal examination of couples' coping strategies as predictors of adjustment to breast cancer. J Fam Psychol 2011; 25: 963-972. (PMID: 21928887) [CrossRef]

28. Muzzatti B, Annunziata MA. Body image assessment in oncology: An up date review. Support Care Cancer 2016; 25: 1019-1029. (PMID; 27988866) [CrossRef]

29. Archangelo SDCV, Sabino Neto M, Veiga DF, Garcia EB, Ferreira LM. Sexuality, depression and body image after breast reconstruction. Clinics 2019; 74: e883. (PMid:31166474) [CrossRef]

30. Koçan S, Gürsoy, A. Body Image of Women with Breast Cancer After Mastectomy: A Qualitative Research. J Breast Health 2016; 12: 145-150. (PMID: 28331752) [CrossRef]

31. Chow R, Pulenzas N, Zhang L, Ecclestone C, Leahey A, Hamer J, DeAngelis C, Bedard G, McDonald R, Bhatia A, Ellis J, Rakovitch E, Vuong S, Chow E, Verma S. Quality of life and symptom burden in patients with breast cancer treated with mastectomy and lumpectomy. Support Care Cancer 2016; 24: 2191-2199. (PMID: 26563182) [CrossRef]

32. Cohen M, Anderson RC, Jensik K, Xiang Q, Pruszynski J, Walker AP. Communication between breast cancer patient sand their physicians about breast-related body image issues. Plast Surg Nurs 2012; 32: 101105. (PMID: 22929196) [CrossRef]

33. Crowley SA, Foley SM, Wittmann D, Jagielski CH, Dunn RL, Clark PM, Griggs JJ, Peterson C, Leonard M, An LC, Wei JT, Montie JE, Janz NK. Sexual health concerns among cancer survivors: Testing a novel information-need measure among breast and prostate cancer patients. J Cancer Educ 2016; 1: 588-594. (PMID: 26076657) [CrossRef]

34. Jun EY, Kim S, Chang SB, Oh K, Kang, HS, Kang SS. The effect of a sexual life reframing program on marital intimacy, body image, ands exual function among breast cancer survivors. Cancer Nurs 2011; 34: 142-149. (PMID: 20885305) [CrossRef]

35. Den Ouden ME, Pelgrum-Keurhorst MN, Uitdehaag MJ, De Vocht HM. Intimacy and sexuality in women with breast cancer: professional guidance needed. Breast Cancer 2019; 26: 326-332. (PMID: 30361832) [CrossRef]

36. Champion VL, Ziner KW, Monahan PO, Stump TE, Cella D, Smith LG, Bell CJ, Von Ah D, Sledge GW. Development and psychometric testing of a breast cancer survivor self-efficacy scale. Oncol Nurs Forum 2013; 40: 403. (PMID: 24161644) [CrossRef]

37. Przezdziecki A, Sherman KA, Baillie A, Taylor A, Foley E, Stalgis-Bilinski K. My changed body: breast cancer, body image, distress and self-compassion. Psychooncology 2013; 22: 1872-1879. (PMID: 23203842) [CrossRef]

38. Widianti MO, Yona S, Waluyo A. Body Image, Social Support, Effects of Chemotherapy, and Sexual Desire in Breast Cancer Patients. J Int Dent Med Res 2019; 12: 323-330. 